\title{
The Performance of China Stock Market, Based on the Analysis of Implicit Transaction Cost
}

\author{
Qing Zhang \\ School of Economics, Jinan University, Guangzhou, China \\ Email: QINGZH1028@163.com
}

How to cite this paper: Zhang, Q. (2018) The Performance of China Stock Market, Based on the Analysis of Implicit Transaction Cost. American Journal of Industrial and Business Management, 8, 1050-1064. https://doi.org/10.4236/ajibm.2018.84072

Received: March 26, 2018

Accepted: April 27, 2018

Published: April 30, 2018

Copyright $\odot 2018$ by author and Scientific Research Publishing Inc. This work is licensed under the Creative Commons Attribution International License (CC BY 4.0).

http://creativecommons.org/licenses/by/4.0/

\section{(c) (i) Open Access}

\begin{abstract}
This paper is based on the stocks listed on the Shanghai and Shenzhen stock exchanges for full year in the early period of 1992 to the end of 2016, using Hasbrouck sampling method to estimate the implicit transaction cost of Chinese order-driven market, and observing the performance of stock market and affecting factors based on the implicit transaction costs. Empirical results show: the implicit transaction cost is an unavoidable cost for investors, and the performance of China stock market is not ideal. Finally, it is suggested that China stock market should improve the trading system, strengthen the information disclosure system and optimize the equity system of listed companies.
\end{abstract}

\section{Keywords}

Market Performance, Implicit Transaction Cost, Gibbs Sampling Model, Influencing Factor

\section{Introduction}

Financial market micro-structure theory originated from the late 1960s. It is a key emerging branch of modern finance, and is one of the most popular financial problems in the past half century. Market performance is the main component of this theory. For a long time, the market performance is a comprehensive concept, and there is still no a unified index to measure it. Most of the researches are from multiple perspectives, which can only be quantitatively analyzed from six aspects: liquidity, stability, fairness, effectiveness, transparency and reliability. Therefore, how to evaluate the performance of the market systematically is an important basis to reflect the core competitiveness of the market, and it can promote market innovation and strengthen market regulation, and it is also a prerequisite for improving the market trading mechanism and making it healthy. 
In the six aspects of measuring the performance of market, liquidity is related to transaction costs directly, while the other five indicators can also reflect the transaction costs. Therefore, the implicit transaction cost can be used to reflect the specific situation of the six different angles as a comprehensive index comprehensively. Implicit transaction cost is usually directly measured by the bid-ask spread in the market-maker system, and it can be decomposed into inventory cost, execution cost and adverse selection cost. But in the order-driven system, the implicit transaction cost does not include inventory costs, and it cannot be measured directly. So the measurement of implicit transaction cost has been gaining more and more attention by many scholars at home and abroad.

In a word, the implicit transaction cost can reflect the performance of stock market comprehensively. It represents the level of flow and stability in the market, and it also explains whether this is effective and fair. It not only affects the investment and financing decisions of enterprises, but also plays a role in the psychology of small and medium investors, which reflects the competitiveness of the whole market. It is a major factor that represents the quality of the stock market. Therefore, the calculation of the implicit transaction cost and the analysis of its influencing factors play an important role in improving the performance of the whole stock market. Accurate understanding and measurement of implicit transaction cost have vital significance to the development of information disclosure system, supervision mechanism and operation performance. The research of this paper has the double meaning of theory and reality.

This paper examines the performance of China stock market from a new perspective, uses a comprehensive indicator to evaluate all aspects of the market scientifically, and enriches the method of analyzing market micro-features. In practice, it analyzes the implicit transaction cost and influencing factors of the China stock market, provides theoretical support for the government to improve the market system and regulate the behavior of market players, which is conducive to the healthy, standardized, efficient development of China stock market. There are some areas for improvement in this article. First of all, this paper cannot describe the changing pattern of implicit transaction cost within one day. Secondly, it ignores other factors such as price volatility, market depth, and company size when studying the influencing factors of China stock market performance. Finally, the Gibbs sampling method that is suitable for the Chinese market still needs further verification.

This article includes the following parts: the first part is the introduction; the second part is literature review; the third part estimates the implicit transaction cost of Shanghai and Shenzhen a-share market by Gibbs sampling method; the fourth part investigates the main influencing factors of China stock market performance based on the measure of implicit transaction cost; the fifth part summarizes the research results and puts forward policy suggestions accordingly.

\section{Literature Review}

Demsetz (1968) proposed the concept of transaction cost firstly. He differen- 
tiates transaction cost into explicit and implicit in The Cost of Transacting. While explicit transaction cost includes commission and stamp duty, implicit transaction cost is derived from the information asymmetry, which is generally reflected in the transaction price [1]. Since the publication of Demsetz (1968), the focus of bid-ask spread is the quotation drive system mainly, which includes the inventory model and the information model.

The inventory model is the first stage of research. O'Hara (1995) divided the inventory model into three types [2]. The first type was proposed by Mark Garman (1976). He focused on analyzing the relationship between order flow and inventory cost, and pointed out that the randomness of orders resulted in the existence of bid-ask spreads [3]. The second category is the Ho, Stoll (1981) model. They used the dynamic method to study the market maker pricing strategy and considered that market maker pricing is a process that maximizes utility [4]. The third category is the CMSW model proposed by Cohen, Maier, Sehwarta, and Whiteomb (1981). It focuses on the analysis of multiple market makers in the market. In this model, mutual expectations among market makers also interfere with the formation of prices [5]. The information model is the second stage of research. Bagehot (1971) first described the formation of bid-ask spreads based on information asymmetry. He pointed out that market makers will gain a balance when the price is determined, and determine a balanced bid-ask spread [6]. Copeland and Galai (1983) illustrated the adverse selection cost, and used static game model to show the necessity of the bid-ask spread [7]. Glosten and Milgrom (1985) used dynamic game model and discussed the process of market-makers in the quote drive market. They found that price formulation was not affected by the transaction costs [8].

In the estimation of bid-ask spread, Roll (1984) proposed a sequence covariance method for calculating bid-ask spreads. However, this method only measures market order processing costs and ignores adverse selection costs [9]. George, Kaul, and Nimalendran (1991) proposed a new estimation model (GKN model) based on the autocorrelation of expected returns, and used this model to empirically test the NASDAQ market [10]. Lin, Sanger and Booth (1995) analyzed whether the components of the bid-ask spread have the characteristics of economies of scale. The results show that the larger the transaction size, the higher the adverse selection cost and the lower the order processing cost [11]. Ahn et al. (2002) estimated the bid-ask spread using the MMR model and found that both the adverse selection cost and the order processing cost of the Tokyo stock market showed a clear " $U$ " shape [12]. Based on the Roll (1984) model, Hasbrouck (2009) proposed the Gibbs sampling estimation method. This method does not belong to the original covariance model. It is a special Monte Carlo algorithm [13].

The study of implicit transaction costs in China has largely borrowed from foreign research results. Qu Wenzhou and Wu Shinong (2002) described the changing characteristics of implicit transaction costs. The results showed that the intraday data of implicit transaction costs changed in an "L" shape [14]. 
Yang Zhisong and Yao Songyao (2004) estimated the risk of information trading in Shanghai based on the EKOP model, and pointed out that the greater the trading volume, the lower the probability of informational transactions [15]. Lei Jueming and Zeng Yong (2006) decompose the implicit transaction cost into adverse selection cost and order processing cost based on the MMR model. It is pointed out that the reason why the implicit transaction cost is " $\mathrm{L}$ " shape is due to the reverse direction [16]. Tian Jing (2007) studied the implicit transaction costs from the trading volume, and used the LMSW test to find that the degree of information asymmetry in China was positively correlated with the scale of capital [17]. Jiang Guan and Tian Cunzhi (2008) used high-frequency data to estimate the implicit transaction cost of each representative stock based on the Roll model. It was found that implicit transaction cost accounted for a relatively high proportion and was a cost that buyers and sellers could not miss out [18]. Zhang Shiyun and Zhou Jie (2009) used diversification as an indicator to measure the degree of information asymmetry, and found that the industry's non-relevant diversification has a significant impact [19]. Xiao Ruixia and Tian Cunzhi (2012) compared the volatility of the implicit transaction costs of Shenzhen stock market under different market conditions. The results show that implicit transaction cost is greater and fluctuates frequently under the bull market [20]. Tian Cunzhi, Wang Cong, and Wu Su (2015) expanded the joint estimation model based on the Roll model and the GNK model. They found that the implicit trading cost of China's stock market is high, and proposed to implement a hybrid quoting system to improve market performance [21].

At present, there are some defects in the study of implicit transaction costs, both abroad and domestically. In the foreign studies, the first is lack of discussion on the implicit transaction costs of the derivative market. Secondly, the generated theory is mostly directed at the quote-driven system, and the model of the order-driven system is not perfect. Finally, the same problem of implicit transaction cost has different results when using different models. The domestic research started late, so there are several defects. First of all, domestic researchers' analysis of implicit transaction cost is mostly based on foreign theories and there is no localized theoretical development. Secondly, the model of quote-driven system is directly applied to the order-driven market in China. It cannot truly reflect the changes in the implicit transaction costs of the domestic market. Finally, the research methods of foreign countries are not innovated when studying the domestic market, so the results are not accurate. In view of the above points, how to improve the theoretical model and empirical method of market performance and implicit transaction cost are the future development aim and forward goal.

\section{The Estimate of Implicit Transaction Cost}

\subsection{Gibbs Sampling Estimation Model}

The Gibbs sampling estimation method is the estimation model of the implicit transaction cost in the order-driven system proposed by Hasbrouck (2009). It is 
based on the classical price trading co-variance model of Roll (1984) and is a special Monte Carlo algorithm.

Set $m_{t}$ as the intrinsic value of stock, the natural logarithm of the purchase intermediate price in particular. $P_{t}$ is the transaction price on day $t$, which is represented by the closing price, $p_{t}$ is the natural $\log$ of $P_{t} . Q_{t}$ represents the virtual variables of the direction of purchase and sale, $Q_{t}=1$ indicates that the transaction direction is the buyer initiative, $Q_{t}=-1$ indicates that the transaction direction is the seller initiative. $s$ is the implicit transaction cost. The disturbance term is denoted by $u_{t}$. According to the Roll model, it can be obtained:

$$
\begin{aligned}
& m_{t}=m_{t-1}+u_{t} \\
& P_{t}=m_{t}+s Q_{t}
\end{aligned}
$$

According to the relationship between above variables, it can be obtained:

$$
\Delta p_{t}=m_{t}+s Q_{t}-\left(m_{t-1}+s Q_{t-1}\right)=s \Delta Q_{t}+u_{t}
$$

Hasbrouck expanded the Roll model, introduced the yield $r_{m t}$, it can be obtained:

$$
\Delta p_{t}=s \Delta Q_{t}+\beta_{m} r_{m t}+u_{t}
$$

Suppose the price sequence can be broken down, namely $p_{t}=\left(p_{1}, \cdots, p_{t}\right)$. It's impossible to determine the direction of transaction and the value of parameters, but the statistical characteristics of the posterior distribution of the price sequence can be obtained through sampling. The specific operation is to select a $p_{t}$ randomly, then extract randomly from conditional distribution $f\left(\cdot \mid p_{[-1]}\right)$, and replace $p_{t}$ with the extracted value. After multiple sampling, we can obtain a convergent Markov chain. And other unknown variables $Q_{t}, u_{t}, \beta_{m}, s$, if the initial values are set, they can be extracted by their conditional distribution.

In practice, assume that the prior distribution of $s$ is $s \sim N\left(\mu_{s}, \sigma_{s}^{2}\right)$. The prior distribution of $u_{t}$ obeys the normal distribution, $u_{t} \sim\left(0, \sigma_{u}^{2}\right)$. The prior distribution of $\beta_{m}$ is $\beta_{m} \sim N\left(\mu_{\beta}, \sigma_{\beta}^{2}\right), \sigma_{u}^{2}$ obeys gamma distribution, $\sigma^{2} \sim I G(\alpha, \beta) . Q_{t}$ is the symbol of $\Delta p_{t}$.

Next, we set the initial value of the variable. Assume $Q_{1}=+1, \sigma_{u}^{2}=0.004$. Because the value of implicit transaction cost is positive, then $s>0$ and it obeys the normal distribution $c \sim N^{+}\left(0,0.05^{2}\right) . \quad \beta_{m}$ obeys the normal distribution $\beta_{m} \sim N(1,1)$. The variance of $u_{t}$ obeys the gamma distribution $\sigma_{u}^{2} \sim \operatorname{IG}\left(1 \times 10^{-12}, 1 \times 10^{-12}\right)$. The prior distribution of all coefficients is shown in Table 1.

The steps of Gibbs sampling estimation method are as follows:

The first step is to assume that $Q_{1}=+1, \sigma_{u}^{2}=0.004$. The second step is to return $\Delta p_{t}$ to $r_{m t}$, extract $c$ and $\beta_{m}$, calculate the posterior distribution of $s$ and $\beta_{m}$. The third step is to extract $\sigma_{u}^{2}$, calculate the posterior distribution of $\sigma_{u}^{2}$. The fourth step is to extract $Q_{t}$, calculate the posterior distribution of $Q_{t}$. The fifth step is to go back to step two and keep repeating. 
Table 1. Prior distribution.

\begin{tabular}{cc}
\hline Parameter & Prior Distribution and Initial Value \\
\hline$s$ & $s \sim N^{+}\left(0,0.05^{2}\right)$ \\
$\beta_{m}$ & $\beta_{m} \sim N(1,1)$ \\
$\mu_{t}$ & $u_{t} \sim\left(0,0.0004^{2}\right)$ \\
$\sigma_{u}^{2}$ & $\sigma^{2} \sim I G\left(1 \times 10^{-12}, 1 \times 10^{-12}\right)$ \\
$Q_{t}$ & $\Delta p_{t}$ Symbol \\
\hline
\end{tabular}

Under this framework, the Bayesian method is used to build the conditional distribution function. $\Delta p_{t}$ is an $\mathrm{n}$-dimensional interpreted variable. Explanatory variables $\Delta Q_{t}$ and $r_{m t}$ form an order explanatory variable matrix. Coefficient sum is an explanatory variable coefficient.

$$
\Omega_{e}=\left\{\begin{array}{ccc}
\sigma_{u}^{2} & \cdots & 0 \\
0 & \sigma_{u}^{2} & 0 \\
0 & \cdots & \sigma_{u}^{2}
\end{array}\right\}
$$

Assume $\Omega_{e}=\sigma^{2} I$. The parameter $\sigma^{2}$ obeys the gamma distribution $\sigma^{2} \sim \operatorname{IG}(\alpha, \beta)$. The posterior distribution of $\sigma^{2}$ is $\sigma^{2} \sim I G\left(\alpha^{\prime}, \beta^{\prime}\right)$. The posterior distribution parameters are calculated from $\alpha^{\prime}=\alpha+n / 2$ and $\beta^{\prime} \sim\left(\beta^{-1}+\sum u_{i}^{2} / 2\right)^{-1}$. The coefficient $c$ posterior distribution is $c \backslash-N\left(\mu_{c}^{\prime}, \sigma_{c}^{\prime 2}\right)$. The coefficient $\beta_{m}$ posterior distribution is $\beta_{m} \backslash-N\left(\mu_{\beta}^{\prime}, \sigma_{\beta}^{\prime 2}\right)$. The variance of the two components makes up the coefficient variance matrix $\Omega_{b}$. The posterior distribution parameters are calculated from $\mu^{\prime}=\left(X^{\prime} \Omega_{e}^{-1} X+\Omega_{b}^{-1}\right)^{-1}\left(X^{\prime} \Omega_{e}^{-1} y+\Omega_{b}^{-1} \mu\right)$. Since the variable $Q_{t}$ is not observable, it needs to be estimated as follows:

Assume $\Delta p_{t}=s \Delta Q_{t}+\beta_{m} r_{m t}+u_{t}$, known coefficient $s, \beta_{m}$ and $\sigma_{u}^{2}$,

$$
\begin{gathered}
u_{t}=s \Delta Q_{t}+\Delta p_{t}+\beta_{m} r_{m t} \\
u_{t}\left(Q_{t}\right)=s\left(Q_{t}-Q_{t-1}\right)+\Delta p_{t}+\beta_{m} r_{m t} \\
u_{t+1}\left(Q_{t}\right)=s\left(Q_{t+1}-Q_{t}\right)+\Delta p_{t+1}+\beta_{m} r_{m(t+1)}
\end{gathered}
$$

Since the residual $\mu_{t}$ obeys the normal distribution, there are:

$$
\frac{P\left(q_{t}=+1 \mid K, q_{t-1}, q_{t+1}, K\right)}{P\left(q_{t}=-1 \mid K, q_{t-1}, q_{t+1}, K\right)}=\frac{f\left(u_{t}\left(q_{t}=+1\right)\right) f\left(u_{t+1}\left(q_{t}=+1\right)\right)}{f\left(u_{t}\left(q_{t}=-1\right)\right) f\left(u_{t+1}\left(q_{t}=-1\right)\right)}
$$

Simplification gives the posterior probability:

$$
\begin{gathered}
P\left(q_{t}=+1 \mid K, q_{t-1}, q_{t+1}, K\right)=\frac{k}{1+k} \\
P\left(q_{t}=-1 \mid K, q_{t-1}, q_{t+1}, K\right)=1-\frac{k}{1+k}=\frac{1}{1+k}
\end{gathered}
$$

In order to simplify the calculation and exclude the impact of the warm-up period on the cycle results, 1000 cycles were performed. And the results of the first 200 cycles of sampling for each parameter were removed, the average of 800 
samples were used as a point estimate for each parameter.

\subsection{Descriptive Statistics of Hidden Transaction Costs}

This section uses the stocks listed on the Shanghai and Shenzhen A-shares prior to December 31, 2015 as samples. The sample range is from February 1992 to December 2016 for all trading days, using the daily closing price of each stock to estimate the implicit transaction costs. All the data used in this paper comes from the Guotai Security Database. In order to ensure the accuracy of the estimation results, the months which the trading day is less than 15 and the month of allotment are excluded to remove the impact of the suspension and the allotment of shares.

Based on the above research methods and samples, the implicit transaction costs for each month were estimated. This data was obtained by taking the average of the implicit transaction costs of all samples for the month. Figure 1 and Figure 2 depict the monthly trends of the implicit transaction costs on the

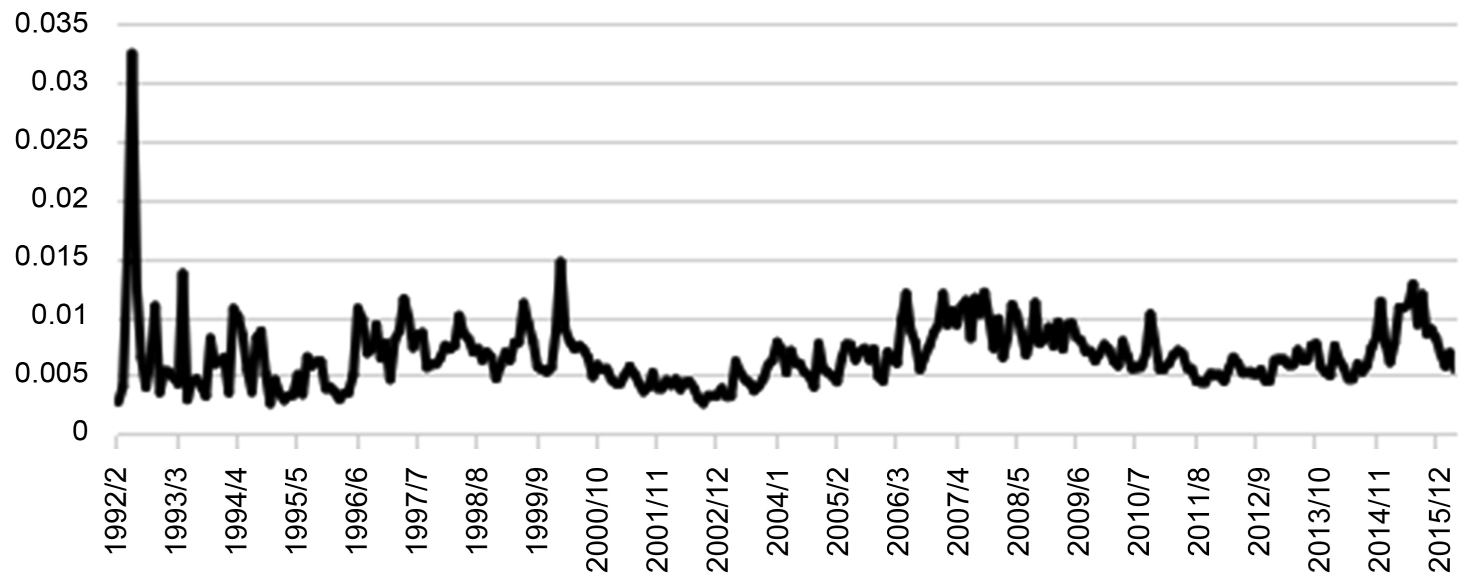

Figure 1. Implicit Transaction cost in Shanghai.

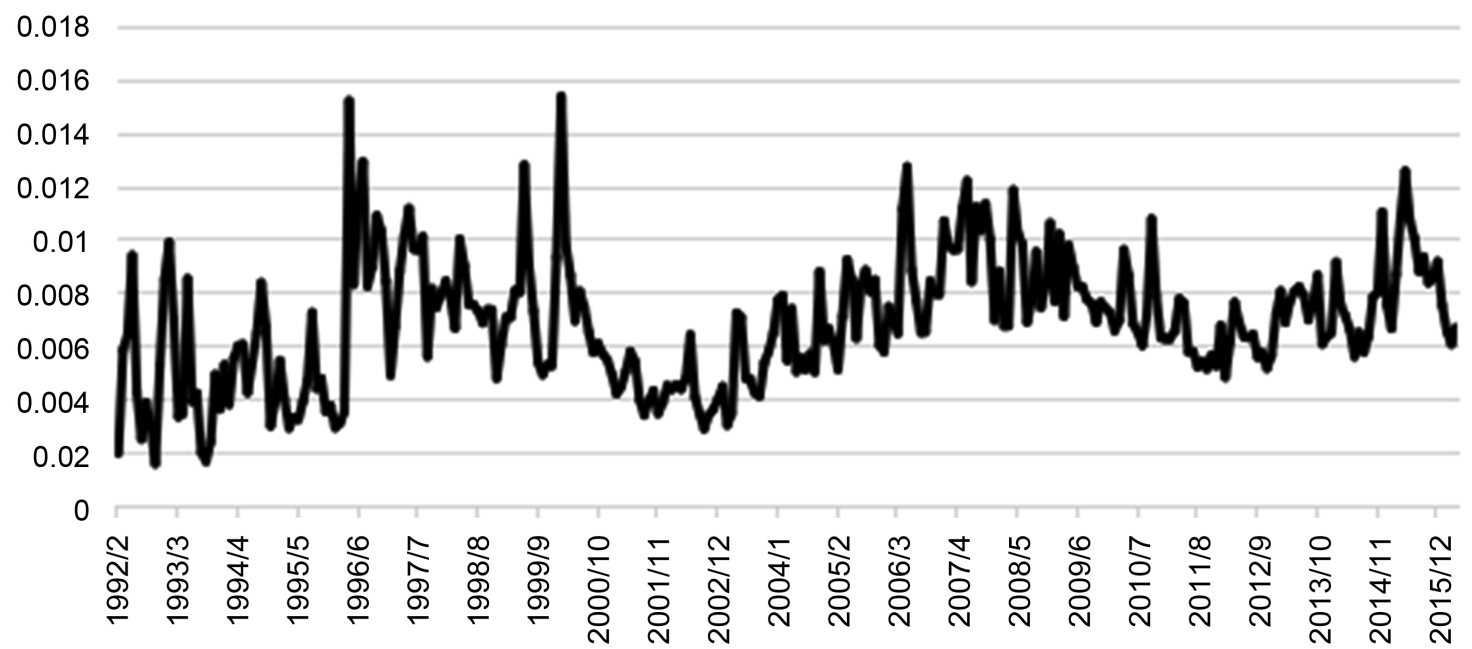

Figure 2. Implicit transaction cost in Shenzhen. 
Shanghai and Shenzhen A-share market from early 1992 to the end of 2016 respectively.

As can be seen from Figure 1, the implicit transaction costs of the Shanghai A-share market reached its historical peak in 1992. This is related to the incomplete trading system and strong speculative atmosphere in the initial stage of market construction. On the whole, the implicit transaction costs of the Shanghai A-share market are mainly concentrated in the range of $0.5 \%$ to $1 \%$, and they fluctuate most in 1992 and then tend to be flat.

As can be seen from Figure 2, the fluctuation range of the implicit transaction costs of the Shenzhen A-share market is generally concentrated within the range of $0.25 \%$ to $1.5 \%$. The minimum value appears in 1993 and the maximum value appears in 1995. In addition, the volatility of the implicit transaction cost is relatively large before 2001, and has slowed since 2001.

Relative to the Shenzhen A-share market, the volatility of the Shanghai A-share market is even more severe. However, the trend of changes in the implicit transaction costs of two markets is consistent basically after 1996. This is mainly because the government began to impose a limit of price fluctuations in December 1996, which has reduced the market's irrational speculation and has had a very big impact on the market mechanism. Since 1996, the fluctuations in implicit transaction costs have substantially decreased.

In order to grasp the characteristics and the trend of the implicit transaction cost clearly, Table 2 and Table 3 are the descriptive statistics of the implicit transaction costs on the Shanghai and Shenzhen A-share markets.

From the perspective of the average annual value, the implicit trading cost of the Shanghai and Shenzhen A-share market are generally within the range of $0.5 \%$ to $1 \%$. The minimum for the Shanghai A-share market was $0.3769 \%$ in 2002, and maximum was $0.9354 \%$ in 1992 . While Shenzhen A-shares had the lowest level of $0.4162 \%$ in 2002, and had the highest level of $1.095 \%$ in 2007. From the median point of view, the implicit trading costs in Shanghai and Shenzhen A-share markets are also in a range-boundary trend. From the perspective of standard deviation, the volatility of implicit transaction cost in Shanghai A-share market had an extreme big value in 1992. It was relatively flat in the later period. The volatility of the implicit transaction cost in Shenzhen A-share market was relatively large before 2001 and was relatively stable after 2001.

\section{Factors Affecting China Stock Market Performance}

\subsection{Study Sample and Variable Description}

In this section, we will use implicit transaction cost as the representative to explore the factors that influence the performance of China stock market. The sample is all stocks listed on the Shanghai and Shenzhen A shares at the end of 2015. The sample range is from early 2005 to the end of 2016. The data includes the equity structure data of the listed company and the transaction data of the 
Table 2. Descriptive statistics of Shanghai.

\begin{tabular}{cccccccc}
\hline Year & Average & Median & Std. Dev. & Maximum & Minimum & Skewness & Kurtosis \\
\hline 1992 & 0.009354 & 0.006233 & 0.032457 & 0.002713 & 0.008621 & 2.213949 & 5.491226 \\
1993 & 0.005631 & 0.004738 & 0.013656 & 0.002927 & 0.002886 & 2.221417 & 5.702511 \\
1994 & 0.006444 & 0.005991 & 0.010659 & 0.002591 & 0.002702 & 0.163529 & -1.360430 \\
1995 & 0.004499 & 0.003934 & 0.006547 & 0.002864 & 0.001349 & 0.430332 & -1.683341 \\
1996 & 0.006378 & 0.006670 & 0.010673 & 0.002930 & 0.002674 & 0.193311 & -1.315777 \\
1997 & 0.007616 & 0.007684 & 0.011485 & 0.004647 & 0.001976 & 0.406300 & -0.273932 \\
1998 & 0.007311 & 0.007261 & 0.010072 & 0.004715 & 0.001294 & 0.211021 & 2.010776 \\
1999 & 0.007102 & 0.006599 & 0.011126 & 0.005237 & 0.001798 & 1.098938 & 0.774517 \\
2000 & 0.007531 & 0.007223 & 0.014649 & 0.004868 & 0.002578 & 2.065411 & 5.470002 \\
2001 & 0.004496 & 0.004316 & 0.005732 & 0.003600 & 0.000650 & 0.499388 & -0.653494 \\
2002 & 0.003769 & 0.003826 & 0.004634 & 0.002598 & 0.000683 & -0.256488 & -1.249085 \\
2003 & 0.004592 & 0.004472 & 0.006239 & 0.003172 & 0.001073 & 0.352303 & -1.142042 \\
2004 & 0.005979 & 0.005673 & 0.007804 & 0.004004 & 0.001200 & 0.243166 & -0.953252 \\
2005 & 0.006202 & 0.006363 & 0.007625 & 0.004438 & 0.001210 & -0.422096 & -1.556737 \\
2006 & 0.007913 & 0.007630 & 0.011946 & 0.005475 & 0.001849 & 0.798542 & 0.524090 \\
2007 & 0.009206 & 0.010345 & 0.012063 & 0.007308 & 0.001491 & -0.602418 & -0.347380 \\
200 & 0.008755 & 0.008402 & 0.01160 & 0.006531 & 0.001524 & 0.252643 & -0.912064 \\
2009 & 0.007826 & 0.007543 & 0.009523 & 0.006215 & 0.001097 & 0.522433 & -0.875098 \\
2010 & 0.006757 & 0.006429 & 0.010194 & 0.005483 & 0.001375 & 1.519208 & 2.597941 \\
2011 & 0.005551 & 0.005490 & 0.007105 & 0.004328 & 0.000958 & 0.358884 & -1.104973 \\
2012 & 0.005244 & 0.005145 & 0.006532 & 0.004485 & 0.000597 & 0.821042 & 0.789561 \\
2013 & 0.006392 & 0.006283 & 0.007721 & 0.005244 & 0.000735 & 0.608212 & -0.146324 \\
2014 & 0.006457 & 0.005885 & 0.011297 & 0.004654 & 0.001895 & 1.646179 & 3.127615 \\
2015 & 0.009472 & 0.009119 & 0.012769 & 0.006108 & 0.001975 & 0.083887 & -0.770906 \\
2016 & 0.006162 & 0.006110 & 0.007496 & 0.004800 & 0.000890 & -0.057132 & -1.266008 \\
\hline & & & & & & & \\
\hline
\end{tabular}

stocks. The basic data come from the Guotai Security Database. In order to ensure the validity of results, companies that have undergone special treatment or special transfer processing (ST/PT) are excluded.

The explained variable in this paper is implicit transaction costs. The explanatory variables include the corporate structure and stock trading indicators. Corporate structure indexes mainly include equity concentration (CON), institutional shares proportion (PIS) and insider ownership (PNS); stock trading indexes include circulation A shares proportion (LTA) and turnover rate (HSL). In the previous studies, prices and volume have also been involved. These two indicators have a significant impact on implicit transaction cost, so the price (PRI) and volume (VOL) are indispensable research variables. Table 4 reports the names, representative letters, and definitions of each variable.

Using above indicators as explained variables, explanatory variables and control variables, set the panel data model as follows: 
Table 3. Descriptive statistics of Shenzhen.

\begin{tabular}{cccccccc}
\hline Year & Average & Median & Std. Dev. & Maximum & Minimum & Skewness & Kurtosis \\
\hline 1992 & 0.004745 & 0.004232 & 0.009374 & 0.001533 & 0.002594 & 0.575265 & -0.641686 \\
1993 & 0.004540 & 0.003730 & 0.009867 & 0.001620 & 0.002599 & 1.054604 & 0.214155 \\
1994 & 0.005367 & 0.005413 & 0.008348 & 0.002956 & 0.001495 & 0.250490 & 0.088027 \\
1995 & 0.004228 & 0.003919 & 0.007224 & 0.002876 & 0.001195 & 1.509409 & 2.793228 \\
1996 & 0.008669 & 0.008656 & 0.015203 & 0.002887 & 0.003914 & -0.212680 & -0.625579 \\
1997 & 0.008330 & 0.008460 & 0.011151 & 0.004866 & 0.001930 & -0.452799 & -0.645410 \\
1998 & 0.007523 & 0.007425 & 0.009979 & 0.004754 & 0.001282 & -0.190239 & 1.863621 \\
1999 & 0.007155 & 0.007037 & 0.012782 & 0.004892 & 0.002211 & 1.538527 & 3.099795 \\
2000 & 0.007898 & 0.007170 & 0.015366 & 0.005438 & 0.002767 & 1.953555 & 4.640548 \\
2001 & 0.004361 & 0.004219 & 0.005752 & 0.003362 & 0.000757 & 0.503808 & -0.660777 \\
2002 & 0.004162 & 0.004182 & 0.006376 & 0.002847 & 0.000895 & 1.170711 & 2.833184 \\
2003 & 0.005024 & 0.004691 & 0.007202 & 0.002988 & 0.001360 & 0.334532 & -0.870568 \\
2004 & 0.006347 & 0.005916 & 0.008769 & 0.004989 & 0.001294 & 0.634420 & -0.947184 \\
2005 & 0.007293 & 0.007554 & 0.009214 & 0.005084 & 0.001410 & -0.171206 & -1.647571 \\
2006 & 0.008198 & 0.007787 & 0.012718 & 0.006437 & 0.001928 & 1.518924 & 1.895732 \\
2007 & 0.010095 & 0.010141 & 0.012185 & 0.006934 & 0.001417 & -0.884674 & 1.154060 \\
2008 & 0.008692 & 0.008499 & 0.011835 & 0.006713 & 0.001700 & 0.413856 & -0.954495 \\
2009 & 0.008092 & 0.007682 & 0.010180 & 0.006855 & 0.001031 & 1.056812 & 0.275022 \\
2010 & 0.007516 & 0.007035 & 0.010748 & 0.005992 & 0.001448 & 1.289393 & 0.955677 \\
2011 & 0.006022 & 0.005744 & 0.007740 & 0.005103 & 0.000889 & 1.037680 & 0.154227 \\
2012 & 0.006086 & 0.006193 & 0.007604 & 0.004790 & 0.000784 & 0.193090 & 0.003527 \\
2013 & 0.007439 & 0.007600 & 0.008625 & 0.006037 & 0.000786 & -0.436799 & -0.631391 \\
2014 & 0.007303 & 0.006834 & 0.011012 & 0.005568 & 0.001545 & 1.355643 & 1.993890 \\
2015 & 0.009250 & 0.008958 & 0.012551 & 0.006626 & 0.001594 & 0.508100 & 0.549504 \\
2016 & 0.006769 & 0.006598 & 0.008247 & 0.005320 & 0.000881 & 0.196973 & -0.704325 \\
\hline & & & & & & & \\
& & & & & \\
2005 &
\end{tabular}

Table 4. Variable definition and description.

\begin{tabular}{|c|c|c|c|}
\hline Variable & Name & Letter & Definition \\
\hline \multirow[t]{3}{*}{$\begin{array}{l}\text { Explained } \\
\text { Variable }\end{array}$} & $\begin{array}{l}\text { Implicit Transaction } \\
\text { Cost }\end{array}$ & $S$ & \\
\hline & $\begin{array}{c}\text { Equity } \\
\text { Concentration }\end{array}$ & $\mathrm{CON}$ & $\begin{array}{l}\text { The sum of squares of the top ten } \\
\text { shareholding ratio. }\end{array}$ \\
\hline & $\begin{array}{l}\text { Institutional Shares } \\
\text { Proportion }\end{array}$ & PIS & $\begin{array}{l}\text { Total number of institutional } \\
\text { investors/Total share capital }\end{array}$ \\
\hline \multirow[t]{3}{*}{$\begin{array}{l}\text { Explanatory } \\
\text { variable }\end{array}$} & Insider Ownership & PNS & $\begin{array}{c}\text { (State owned shares + Legal person } \\
\text { shares)/Total share capital }\end{array}$ \\
\hline & $\begin{array}{l}\text { Circulation A Shares } \\
\text { Proportion }\end{array}$ & LTA & A shares in circulation/Total share capital \\
\hline & Turnover Rate & HSL & Trading shares/Total share capital \\
\hline Control & Price & VOL & Closing price \\
\hline Variable & Volume & PRI & Volume \\
\hline
\end{tabular}




$$
\begin{aligned}
S_{i, t}= & \alpha+\alpha_{1} \operatorname{CON}_{i, t}+\alpha_{2} P S_{i, t}+\alpha_{3} P N S_{i, t}+\alpha_{4} L T A_{i, t} \\
& +\alpha_{5} H L S_{i, t}+\alpha_{6} \operatorname{VOL}_{i, t}+\alpha_{7} P R I_{i, t}+\varepsilon_{i j}
\end{aligned}
$$

\subsection{Empirical Results and Theoretical Analysis}

According to descriptive statistics, the implicit transaction costs have not changed significantly since 2005 . The value is between 0.01 and 0.004 basically. The mean and median of CON are 0.2011 and 0.1667 respectively, indicating that the equity of listed companies was not very concentrated and decentralized relatively. The minimum value of PNS is 0, and the maximum value is $97.49 \%$. The difference between this two is very large, which indicates that the proportion of insiders holding shares is very different in different enterprises. The median and average of PIS are relatively small, indicating that institutional shares proportion is relatively low. HSL and LTA are relatively large, indicating that the market is highly liquid. Table 5 reports the descriptive statistics of variables in the Shanghai and Shenzhen A-share market.

Taking into account the characteristics of the panel data, the Hausman test of the fixed-effect and random-effect models was conducted in this paper. The sample satisfies the fixed-effect model, and the individual differences of the companies meet the expectations. Therefore, the generalized least squares method is used to perform multiple regression analysis on possible influencing factors. The empirical results are shown in Table 6.

From the analysis of empirical results, the degree of ownership concentration, the proportion of insider holdings, and the stock price have a positive impact on the implicit transaction cost. Institutional holding ratio, turnover rate, ratio of circulating A shares, trading volume have a negative impact on the implicit transaction cost.

Firstly, the high degree of equity concentration can lead to exclusive rights easily. This will not only reduce the efficiency of information, but will also undermine the interests of small and medium investors. In the case of insufficient checks and balances, over-concentration of equity will trigger associations, deepen the asymmetry of information and affect the efficiency of the market. There

Table 5. Descriptive statistics.

\begin{tabular}{cccccccc}
\hline & Average & Median & Std. Dev. & Maximum & Minimum & Skewness & Kurtosis \\
\hline S & 0.006755 & 0.006763 & 0.001614 & 0.010095 & 0.003769 & 0.008506 & -0.815876 \\
CON & 0.2011 & 0.1667 & 0.1372 & 0.722 & 0.0015 & 0.931 & 0.2774 \\
PIS & 0.0693 & 0.0434 & 0.096 & 0.8740 & 0 & 0.035 & 0.1516 \\
PNS & 0.2169 & 0.1003 & 0.2510 & 0.9749 & 0 & -0.8200 & -0.6760 \\
LTA & 0.6452 & 0.6469 & 0.2776 & 1 & 0.025 & -0.1374 & -1.3218 \\
HSL & 596.8042 & 487.512 & 430.5772 & 3010.2978 & 0.0093 & 1.28 & 1.8173 \\
VOL & $2.00 \mathrm{E}+09$ & $1.09 \mathrm{E}+09$ & $3.85 \mathrm{E}+09$ & $2.24 \mathrm{E}+11$ & $2.42 \mathrm{E}+03$ & $2.21 \mathrm{E}+01$ & $1.04 \mathrm{E}+03$ \\
PRI & 15.2389 & 11.4 & 13.8557 & 224 & 0.5 & 3.3586 & 20.4662 \\
\hline
\end{tabular}

Data sources: Guotai security database. 
Table 6. Regression results.

\begin{tabular}{ccccc}
\hline & Coefficient & Std. Dev. & T Value & Significant \\
\hline$\alpha$ & 0.01635 & 0.001567 & 10.348 & 0.00 \\
PIS & -0.000059 & 0.0000141 & -3.75 & 0.00 \\
PNS & 0.004285 & 0.0011597 & 4.75 & 0.00 \\
CON & 0.0075887 & 0.0031537 & 2.43 & 0.00 \\
LTA & -0.0002713 & 0.0002754 & -0.93 & 0.350 \\
HSL & -0.0033566 & 0.0003521 & -9.97 & 0.00 \\
PRICE & 0.006722 & 0.0005843 & 11.63 & 0.00 \\
VOLUME & -0.0036057 & 0.000461 & -7.83 & 0.00 \\
\hline
\end{tabular}

is a negative correlation between equity concentration and market performance.

Secondly, institutional investors have advantages in information collection, professional technology, investment philosophy and financial innovation. They can use their expertise to catch imperceptible information of other traders, plan investment strategy scientifically according to the intrinsic value of stock. Institutional investors have an active role in stabilizing the market, improving market transparency, reducing transaction costs and improving the market performance. There is a positive correlation between institutional ownership and market performance.

Thirdly, internal shareholders participate in the daily affairs of the listed company, and have a large number of undisclosed information. As information owners, it is highly probable that private information will be used to obtain high remuneration for illegal information transactions. Therefore, the higher proportion of internal shareholders will deepen the asymmetry of information, harm the interests of small and medium investors, increase the cost of implicit transactions, and reduce market efficiency. There is a negative correlation between insider ownership and market performance.

Fourthly, the ratio of circulating A shares and the turnover rate represent market liquidity. The higher these two indicators, the stronger market liquidity and the better market operating efficiency. There is a positive correlation between the ratio of circulating A shares, turnover rate and market performance.

Finally, the lower the stock price, the lower the difficulty of buying and selling and the higher the liquidity. There is a negative correlation between prices and market performance. The greater the volume of transactions, the better the liquidity. There is a positive correlation between trading volume and market performance.

To sum up, the degree of ownership concentration, the proportion of insider holdings, and the stock price have a negative impact on the performance of China stock market. Institutional holding ratio, turnover rate, ratio of circulating A shares, trading volume have a positive impact on the performance of China stock market. 


\section{Conclusions}

This paper takes the transaction data of Shanghai and Shenzhen stocks from early 1992 to the end of 2016 as a sample to measure the volatility of the implicit trading cost in the past 30 years. At the same time, based on implicit transaction cost, combined with the company ownership structure, shareholding ratio and individual stock trading data, it analyzes the influential factors of the market performance. The main conclusions are as follows: 1) At the beginning of 1992 to the end of 2016, the implicit transaction cost of Shanghai A-share market was mainly concentrated in $0.5 \%$ to $3.5 \%$, and the implicit transaction cost of Shenzhen A-share market was mainly concentrated in the range of $0.25 \%$ to $1.5 \%$. From the perspective of numerical value, the fluctuation interval of Shenzhen A-share is relatively small. From the perspective of trend, the implicit transaction cost of Shanghai and Shenzhen was relatively consistent after 1995; 2) From 1992 to 2001, the implicit transaction cost of Shanghai and Shenzhen A-share market was relatively large, and their fluctuations tended to be flat after 2001. The change of volatility and the development of China stock market are inseparable. At the beginning of the construction of stock market, there are imperfect trading system, strong speculative atmosphere and the poor market performance. The changes in volatility explain the change of market quality; 3) The degree of ownership concentration, the proportion of insider holdings, and the stock price have a negative impact on the performance of China stock market. Institutional holding ratio, turnover rate, ratio of circulating A shares and trading volume have a positive impact on the performance of China stock market.

According to the research conclusion, we can make the following suggestions.

Firstly, improve the equity system of listed companies. According to the empirical analysis from the perspective of corporate ownership structure in this paper, good ownership structure can improve the enterprise business performance, promote the use of resources, increase the transparency of the market, and improve the market operation efficiency. Therefore, in view of the particularity of Chinese enterprises, we must have clear goals to reduce the company's state-owned shares, and release market liquidity. When improving the ownership structure of the company, it is necessary to formulate supporting measures to achieve a balance between supply and demand. At the same time, it is effective for performance to establish a sound supervision system, and improve the company internal incentive system. To sum up, improving the internal structure of listed companies and increasing their degree of marketization can enable companies to create more wealth, increase the efficiency of resource, and enhance market quality.

Secondly, improve the information disclosure mechanism. The transmission and diffusion of information play an important role in the formation of stock prices. The stock market is an information-centered place. Improving the information disclosure mechanism, creating an environment for information freedom can control adverse selection and moral hazard, make investors more 
objective and rational, and also weaken the asymmetry of information in the market and enhance the market effectiveness. Therefore, a sound information disclosure mechanism plays a crucial role in improving market performance.

Thirdly, improve the market trading system. According to studies at home and abroad, a sound trading system can not only increase the transparency of the stock market, reduce the asymmetry of information, but also ensure the orderly conduct of transactions and realize market risk dispersion. At the present stage, China stock market has continuously renewed its trading system and achieved considerable development in terms of transaction costs and market structure after nearly 30 years of development. However, there is still much room for improvement. Therefore, based on the transaction mechanism to establish credit system is imperative.

\section{References}

[1] Demsetz, H. (1968) The Cost of Transacting Quarterly. Journal of Economics, 82, 33-53.

[2] O'Hara, M. (1995) Market Micro-Structure Theory. Basil Blackwell Cambridge, London, 74-158.

[3] Garman, M. (1976) Market Microstructure. Journal of Financial Economics, 3, 257-275. https://doi.org/10.1016/0304-405X(76)90006-4

[4] Ho, T. and Stoll, H. (1981) Optimal Dealer Pricing under Transactions and Return Uncertainty. Journal of Financial Economics, 9, 47-73. https://doi.org/10.1016/0304-405X(81)90020-9

[5] Cohen, K., Maier, S., Schwartz, R. and Whitcomb, D. (1981) Transactions Costs, Order Placement Strategy, and Existence of the Bid-Ask Spread. Journal of Political Economy, 89, 287-305. https://doi.org/10.1086/260966

[6] Bagehot, W. (1971) The Only Game in Town. Financial Analysts Journal, 27, 12-14. https://doi.org/10.2469/faj.v27.n2.12

[7] Co Peland, T. and Galai, D. (1983) Information Effects on the Bid-Ask Spread. Journal of Finance, 38, 1457-1469.

[8] Glosten, L. and Milgrom, P. (1985) Bid, Ask, and Transaction Prices in a Specialist Market with Heterogeneously Informed Traders. Journal of Financial Economics, 13, 71-100. https://doi.org/10.1016/0304-405X(85)90044-3

[9] Roll, R. (1984) A Simple Implicit Measure of the Effective Bid-Ask Spread in an Efficient Market. Journal of Finance, 30, 1127-1139. https://doi.org/10.1111/j.1540-6261.1984.tb03897.x

[10] George, T., Kaul, G. and Nimalendran, M. (1991) Estimation of the Bid-Ask Spread and Its Components: A New Approach. Review of Financial Studies, 4, 623-656. https://doi.org/10.1093/rfs/4.4.623

[11] Lin, J., Sanger, G. and Booth, G. (1995) Trading Size and Components of the Bid-Ask Spread. Review of Financial Studies, 8, 1153-1183. https://doi.org/10.1093/rfs/8.4.1153

[12] Ahn, H.J., Cai, J., Hamao, Y. and Ho, R. (2002) The Components of the Bid-Ask Spread in a Limit Order Market: Evidence from the Tokyo Stock Exchange. Journal of Empirical Finance, 9, 399-430. https://doi.org/10.1016/S0927-5398(02)00003-8

[13] Hasbrouck, J. (2009) Trading Costs and Returns for U.S. Equities: Estimating Effec- 
tive Costs from Daily Data. Journal of Finance, 64, 1445-1477. https://doi.org/10.1111/j.1540-6261.2009.01469.x

[14] Qu, W.Z. and Wu, S.N. (2002) Analysis of the Characteristics of the Microstructure of China's Stock Market. Economic Research Journal, No. 1, 56-63.

[15] Yang, Z.J. and Yao, S.Y. (2004) Shanghai Stock Exchange Spread and Information Exchange Empirical Study. Journal of Financial Research, No. 4, 45-56.

[16] Lei, J.M. and Zeng, Y. (2006) An Analysis of Spreading Bid of Shanghai Stock Market. Systems Engineering, No. 6, 74-80.

[17] Tian, J. (2007) Research on Information Asymmetry of Chinese Stock Market Based on Trading Volume Model. Journal of Tianjin University, No. 11, 524-529.

[18] Jiang, G. and Tian, C.Z. (2008) An Empirical Study on the Implicit Trading Cost of Shanghai Stock Market Based on High Frequency Data. Statistics and Decision, 6, 137-139.

[19] Zhang, S.Y. and Zhou, J. (2009) The Influence of the Diversification of the Company on the Level of Asymmetric Information. Journal of Shanxi University of Finance and Economics, No. 9, 80-86.

[20] Xiao, R.X. Tian, C.Z. (2012) The Impact of Policy Events on the Covert Transaction Costs of Shenzhen A Shares. Jinan University, Guangzhou.

[21] Tian, C.Z., Wang, C. and Wu, S. (2015) The Operation Performance of Quotation System in China's Stock Market-Based on the Analysis of Implicit Trading Cost and Information Asymmetry. Journal of Financial Research, No. 5, 148-161. 